\title{
Toward an Integrated Framework of Information and Communication Behavior: College Students' Information Resources and Media Selection
}

\author{
Soo Young Rieh
}

School of Information, University of Michigan, 1085 S. University Avenue, Ann Arbor, MI 48109-1107; Tel: 734-647-8040 rieh@umich.edu

This study investigated college students' selection of information resources and engagement in information activities from the perspective of an integrated framework of information and communication behavior, by examining students' interactions with many different types of information resources and media across their school, personal, entertainment, problem solving, and other daily routines. Both web-based diaries and semi-structured interviews were used to capture students' information behavior in natural settings. The subjects logged into a web-based diary and recorded the details of their most important information seeking activity on that day by responding to eleven questions including information seeking topic, resources used, time taken, difficulty, familiarity, and confidence. Two hundred and forty-five information seeking episodes reported by twenty-four subjects from three different colleges and universities were collected over a ten-day period. Findings indicate that the students used multiple information resources in one information seeking episode to verify the content in, often, both information and communication behaviors. The results also reveal that information seeking can be better understood from a social framework because students were aware that human information behavior is influenced by other people's opinions and recommendations and may also affect other people's lives.

Introduction

With the development of the Internet and web search engines, it can be assumed that it is quite easy for most people to find information they need. It certainly has become easy to access information. However, it does not necessarily mean that people have easier time finding information for which they are looking. In fact, many people might complain of overload, confusion, and frustration in the process of information seeking. Two sub-processes of information seeking in particular pose challenges to most people. One is how to evaluate information and make judgments of usefulness and credibility after they obtain the information. The other is where to go to find what they need given so many choices of available media and resources. The problem of evaluating information in the process of information seeking has been reported elsewhere (Rieh \& Hilligoss, in press). This paper focuses on the problem of information resources and media selection.

The information seeking process has been traditionally defined as a series of activities: recognizing an information problem, defining the problem, choosing a search system, formulating a query, executing the search, examining the results, and extracting information (Marchionini, 1995). Marchionini's framework 
presents a broad process of information seeking including information problems, seeking, evaluation, and use beyond the limited notion of information retrieval. In the current information-intensive environment, people employ various information seeking strategies in interacting with many different information types, formats, and sources in diverse media. Therefore, an even broader framework is needed, one that includes not only interacting with information systems in which information is stored and represented but also with communication in which the exchange of information and creation of new meaning are accomplished through interactions among social actors (Rice, McCreadie, \& Chang, 2001).

An integrated framework of information and communication behavior is not an entirely novel concept in the field of information science. For instance, Buckland (1991) claimed that "interpersonal communications and mass communications clearly ought to be within our scope" (p. 8), meaning that information and information systems should be viewed broadly. Rice, McCreadie, and Chang (2001) explicitly argue that "accessing and browsing information and communication are highly consequential and multidimensional aspects of the information user's entire experience" (p. 3). Cool and Belkin (2002) distinguished communication behavior from information behavior in their classification of interaction with information. According to them, communication behaviors refer to those behaviors that an individual or group engage in during communicative interactions with another person or persons, while the primary goals of information behaviors are engagement with information objects or groups of information objects. Cool and Belkin claim that they needed to maintain both types of behaviors within the integrated scheme because some combinations of information behaviors and communication behaviors would arise.

People's information seeking rarely occurs in isolation from other people (Hargittai \& Hinnant, 2006). In their daily lives, people seek and use information with the help of their social support networks. Seeking information from interpersonal sources, especially from people like themselves, is well known practice in the field of human information behavior (Harris \& Dewdney, 1994). Harris and Dewdney also point out that the most frequently accepted theory is the principle of least effort, also known as Zipf's law, which states that people tend to solve their information problems in the "easiest and least painful way" (Harris \& Dewdney, p. 22). The Internet has influenced people's information seeking not only by offering a tremendous amount of information but also by providing easy access to other people. As a result, the boundaries of information behavior and communication behavior are blurring.

This study examines a series of information activities in the context of everyday life information seeking from the perspective of an integrated information and communication behavior framework. To investigate information activities in the broadest context of information and communication behaviors, the research had to be designed in such a way as would allow inclusion of all types of information resources accessed through a variety of media ranging from face-to-face interpersonal communication to Web search engines. To capture both information and communication behaviors in natural settings, the self-reporting diary and in-depth interviews were therefore used as data collection methods.

The sampled population of this study is college students. Given that the personal computer has been in use for more than two decades and the Web for more than a decade, today's college students represent the first generation to "grow up digital" (Tapscott, 1997). Computers were already commonplace when they were born, and the Internet has been available since they were elementary school students. According to the Pew Internet and American Life Project's survey conducted in 2002, 20\% of college students started using computers between the ages $5-8$, and virtually all of today's college students were using computers by the time they were 16-18 years old (Jones, 2002). Considering that this survey 
was conducted five years ago, it is presumed that an even greater percentage of today's college students started using computers and the Internet in their early years. Therefore, the ways that college students use new digital media to seek for and communicate with others may fundamentally differ from that of older generations.

The purpose of this research was to better understand the types of information resources and media that college students select to achieve their various information seeking goals ranging from academic achievement, personal information need, entertainment, and problem solving. It also intends to identify the types of resources and media with respect to information seeking tasks as they pertain subject searching, question answering, fact retrieval, known item searching, and advice/recommendation/opinion. Specifically, the following research questions are addressed:

- How do college students select information resources and media differently depending on their information seeking goals and tasks?

- To what extent do they rely on online information to find information for their important information problems?

- Do their information seeking strategies demonstrate an integrated framework of information and communication behavior?

\section{Related Literature}

The report from the Pew Internet and American Life Project (Jones, 2002) demonstrated that use of the Internet has effectively been integrated into college students' daily routines. The respondents in their study reported that the Internet has had a positive impact on their college academic experience given the extent to which it has changed the ways in which they interact with others as well as with information in the course of engaging in their studies. They also reported that they used the Internet nearly as much for social communications as they did for learning and education. The limitation of the Pew survey is that it examines only the use of the Internet in academic settings. Furthermore, it does not focus on how the Internet is used along with more traditional information resources and media such as print materials and face-to-face interpersonal communications.

A number of researchers and practitioners have concerned themselves with the extent to which college students use online resources for their assignments. For instance, Valentine (2001) reported that students focus considerable time and energy attempting to figure out the proverbial "what the professor wants" and so look for "what they perceive to be the most time-effective and cost-effective methods of finding information." (p. 108). That is, they use what is most familiar and easiest to obtain. Based on a survey of 156 undergraduate students, Dilevko and Gottlieb (2002) examined the types of library resources employed when completing assignments and essays. The findings indicate that their study subjects used both online sources and print sources in their assignments: while online resources were used by $63.9 \%$ of undergraduates at least $75 \%$ of the time, $44.2 \%$ still used print book sources and $\mathbf{4 5 . 2} \%$ print journal sources at least $75 \%$ of the time for their assignments.

When studying students' information behavior, however, it is important to include both everyday life as well as academic contexts because they can inform one another and are thus tightly interwoven (Given, 2002). Although her informants were limited to undergraduate students 21 years of age or older, Given's study appears to have a number of implications for efforts to achieve a holistic picture of typical college students' information seeking. As with the informants in Given's study, most college students exhibit an extensive overlap between academic and everyday information needs and seeking. According to Given, 
the decision to seek academic information can be initiated by knowledge acquired through everyday life information seeking in other situations and vice versa.

Julien and Michels (2000) collected the diary entries from nine participants for ten weeks and conducted interviews in New Zealand. They found that students used 3.4 sources on average for each instance of information seeking. For both personal and work situations, the participants approached another person in in 54-57\% of the cases. For their school-related information seeking, print sources were approached first in $45 \%$ of the cases. Electronic information resources were the second most popular for school-related cases but the least frequently used for personal and work-related information seeking cases. It can be argued that their data is rather out-of-date and might not reflect the current information access environments. In a more recent study, however, Weiler (2005) supported Julien and Michels' findings given that her study participants also relied on other people as information sources because they preferred discussing information needs with a "real person" rather than locating all the needed information on their own.

These findings contradict the results of Graham and Metaxas' (2004) research which examined college students' reliance on the Internet. They found that $98 \%$ of students included Internet sources when asked to conduct research though they could use other kinds of resources. They also discovered that students often turned to a search engine immediately and exhibit high confidence in search engines.

Despite the mixed findings on college students' information seeking behaviors, there are a few identifiable trends. Doubtlessly today's college students prefer online resources both from library electronic resources and from the general Web because they prefer to find information "as quickly and with as little effort as possible (Shenton \& Dixon, 2004, p. 192)." However, they still rely on "real people" given that the Internet provides greater connectivity to the social environment. As students engage in a variety of information seeking tasks in their academic work and everyday life, they tend to choose certain information resources and strategies depending on the types of information seeking goals and tasks they target. As Dresang (2005) pointed out, researchers need to focus on new human information behaviors nurtured and facilitated by the digital environment. The next sections will examine the new patterns and strategies of information seeking as they have emerged in the current information-intensive environment.

\section{Research Design}

\section{Information Seeking Diary}

Self-reporting diaries serve the researcher both as data and as a source for generating questions in a semi-structured interview (Zimmerman \& Wieder, 1977). While this method has been employed most extensively in other fields such as health care (e.g., Morrison, Leigh, \& Gillmore, 1999), diaries have also proven useful to a number of library and information science (LIS) researchers given that the method permits collection of a wealth of detailed, actual information behaviors in specific context (Toms \& Duff, 2002).

LIS researchers have employed diaries as a substitute for direct observation to collect data on information seeking activities that arise naturally in work settings (Byström, 2002; Cool \& Belkin, 2002; Xie, 2006), school (Kuhlthau, 2004), or at home (Rieh, 2004). Byström (2002) used semi-structured task diaries to gather details about information seeking tasks, including perceptions of the complexity and frequency of the tasks, actual steps involved in seeking the information, and evaluations of the sources selected. Cool and Belkin (2002) provided their study participants with Activity Notes forms which they 
used to record the details and intentions behind the information seeking activities in which they engaged over the course of a single day. Xie (2006) asked participants to keep an information interaction diary in which they were instructed to record two tasks over the course of a two-week period. Participants made note of the task itself, time spent on the task, information systems and resources consulted, specific queries used, and reflections on the outcome of their efforts. Kuhlthau's (2004) study participants also kept "search logs" in which they recorded the names of the sources used, procedures for finding sources, and whether sources were useful, highly useful, or not useful. Finally, Rieh (2004) provided her participants with a search activities diary in which they recorded their Web information seeking over the course of 3-5 days. In each of these studies, the diary data were then used to formulate questions and elicit deeper details during interviews.

This study also employed the diary to gather details about college students' information seeking activities and then used the data from the diary to guide an in-depth interview. Unlike previous studies, however, the study reported here gathered diary data over a longer period of time (10 days) and for a greater range of activities that included work, school, and personal interest. Once a day for ten consecutive days, subjects logged into a web-based, password-protected diary and recorded the details of what they considered their most important information seeking activity that day. The written instructions in the diary were: "Think about situations today in which you needed to find information. Choose the one that was most important to you; then answer the following questions, providing as much detail as you can." The diary collected this data from responses to eleven questions, seven of which were open-ended questions about the activity: (1) the information sought; (2) the need that motivated the information seeking; (3) the resources used to solve the need; (4) the steps taken to find the information; (5) the intended use of the information; (6) any remaining, unmet, or additional need realized after the search; and (7) additional comments. Another question inquired as to how much time subjects spent in seeking for the information. Finally, three scales were used to gather data about the subjects' familiarity with the topic prior to the searching, level of confidence after the seeking was completed, and rating of the overall difficulty of the activity.

When we recruited the subjects from three different institutions in a Midwestern state including a large research university, a regional university, and a two-year community college, we had an information session with each of subjects so that they became familiarized with the study, learned about the role of the diary, and received a password to their log-in web-based diary. One of the advantages of the web-based diary entries was that we were able to monitor the subjects' progress on the diary for a period of ten days. A few subjects failed to provide diary entries for multiple days; in these instances, we sent email reminders encouraging them to continue recording their activities. There were only two instances in which subjects failed to complete their diaries.

\section{Short Questionnaire and In-Depth Interview}

At the conclusion of the ten days, an interviewer met one-on-one with each subject for a semi-structured interview on the ten information seeking episodes. The interviews were conducted at the subjects' schools in small, private study rooms located in a campus library. These locations were used to provide a neutral, comfortable, and conveniently accessible environment.

Before the interview, each subject first completed a questionnaire on demographic information (major, age, gender), general use of the Internet, and frequency of Internet applications such as email, instant messaging, searching, news, and games. The subjects also responded to the question about how they 
had been using the university library online catalog as well as their experience of attending a training program provided by the university or high school library.

On completion of the questionnaire, subjects were provided printed copies of their diary data to which they could refer during the interview. The interviewer initiated the interview about the information problem reported in the diary. The core questions of the interview were to ask the subjects to describe their information seeking process, resources selected, and plans for information use. Other questions included information quality, cognitive authority, difficulty, and confidence and those are reported in elsewhere (Rieh \& Hilligoss, in press). All of these questions were repeated for each activity entered in the diary. While the interviews focused on the ten recorded activities, additional activities not recorded in the diaries were occasionally discussed as they arose during the interviews. Each interview lasted about one and a half hours and was tape recorded.

\section{Participants}

Between Fall 2005 and Summer 2006, twenty-four undergraduate students from three institutions completed their diaries and participated in the interviews. Of the twenty-four subjects who went on to complete the study, thirteen were students at the large research university, three attended the regional university, and eight were enrolled in the community college. Fourteen were female and ten were male. Half of the subjects were in their first year of college, and their average age was 21.8 years. Eleven were eighteen years old, three were nineteen years old, and a few others were in their early twenties. The average age appears slightly high given the inclusion of three non-traditional students from the community college and regional university: their ages were twenty-nine, thirty-one, and forty-three. The subjects represented a fairly diverse sample as evidenced by the fact that they attended three very different educational institutions and were enrolled in a variety of academic majors including pre-medicine, business, film studies, nursing, English, construction technology, education, computer engineering, dance, and others.

Prior to the interviews, the subjects completed a short questionnaire that gathered data about their use of the Internet. When compared with data from the Pew Internet and American Life Project (Jones, 2002), the subjects in this study appeared to be fairly representative in terms of their Internet use. On average, they claimed to use their institution's online library catalog system approximately 0.75 hours weekly and the Internet 3.6 hours daily. Similarly, the Pew study found that nearly three-quarters (73\%) of college students use the Internet more than they did their campus library. Twenty-one $(87.5 \%)$ of the subjects said they used email multiple times daily, a response comparable to the Pew study which found $72 \%$ checked their email daily. Other uses of the Internet reported by subjects include searching for information for personal use one or more times daily $(n=17)$ and searching for information for school work one or more times daily $(n=14)$. Seventeen subjects $(71 \%)$ said they used instant messaging one or

more times weekly. Eight subjects (33\%) claimed they used the Internet for playing games one or more times weekly while on average, subjects used the Web for news information four or more times weekly.

\section{Data Analysis}

The audiotapes of the twenty-four interviews were transcribed. Given that each subject addressed ten information seeking episodes, the data set included a total of 245 episodes representing a variety of information activities. A coding scheme composed of user goals, tasks, and resources/media used in information activities was developed. Subjects' information seeking processes in general and information seeking strategies in particular were identified. The content analysis method was then 
employed as a technique for identifying and characterizing information seeking strategies as well as information resources or media chosen.

\section{Results}

\section{Information Seeking Goals and Resources/Media Selection}

Understanding information seeking goals is the first step in analyzing information seeking behaviors given that it is goals that motivate people to undertake information seeking activities. According to Xie (2000), the several levels of user goals range from long-term goals (personal goals over a long period of time), and leading search goals (current information task-related goals) to current search goals (specific search results sought) and interactive intentions (subgoals to be achieved during the seeking process). Of primary concern here were the long-term goals because they tend to remain the same while current search goals and interactive intentions can change during the process (Rieh, 2004; Xie, 2000).

Table 1. Information seeking goals and resources/media Used

\begin{tabular}{|c|c|c|c|}
\hline Goal & $\mathbf{N}(\%)$ & Resources used in total & Resources used on average \\
\hline Personal information need & $99(40.4 \%)$ & 239 & 2.41 \\
\hline Academic achievement & $82(33.5 \%)$ & 185 & 2.26 \\
\hline Entertainment & 42 (17.1\%) & 88 & 2.09 \\
\hline Problem solving & $12(4.9 \%)$ & 27 & 2.25 \\
\hline Routines & $10(4.1 \%)$ & 22 & 2.20 \\
\hline Total & 245 (100\%) & 561 & 2.24 \\
\hline
\end{tabular}

The information seeking goals reported in the diaries and discussed in the interviews can be categorized as follows: (1) personal information need, (2) academic achievement, (3) entertainment, (4) problem solving, and (5) routines. The category of personal information need refers to the cases in which subjects deal with personal information problems such as nutrition, health, shopping, bus schedules, housing, restaurants, phone carriers, etc. The academic achievement category was set up for the cases of research projects, homework, class scheduling, exam dates, and course-related questions. The entertainment category was created for episodes in which subjects talked about movies, games, and sports. The difference between the personal information need and entertainment categories is the goals of information seeking. If the subject was seeking information out of curiosity or to enjoy himself/herself, the activity was categorized as entertainment. If the subject needed some information in order to undertake certain actions (e.g., send a gift to a family member, rent an apartment, start a diet, etc.), it was coded as personal information need. The category of problem solving refers to the cases in which the subjects described episodes that required high-order cognitive processing beyond simple information finding. The examples include one in which a person needed to find out why she was recorded as being an inactive student when she was checking her student account balance and another in which a person needed to contact a staff member because the website in which she was uploading her resume crashed several times. Still another subject arranged for a cab to pick him up but the cab had not arriving. The cases falling into the routines category included subjects checked out news, weather, or stock information to keep up to date.

As seen in Table 1, the subjects reported personal information need most frequently (40.4\%), followed by academic achievement (33.5\%). Because subjects were asked to select their "most important" 
information seeking episodes, routines were not included to a great extent in the diary (4.1\%). On average, subjects employed 2.24 information resources per information seeking episode. It was noted that the number of information resources employed did not dramatically differ across the types of goals.

Table 2. Information seeking goals and resources/media selected

\begin{tabular}{|c|c|c|c|c|c|}
\hline Resource/Medium & $\begin{array}{c}\text { Personal information } \\
\text { need }\end{array}$ & $\begin{array}{c}\text { Academic } \\
\text { achievement }\end{array}$ & Entertainment & $\begin{array}{l}\text { Problem } \\
\text { solving }\end{array}$ & Routines \\
\hline Human Resources & $67(28 \%)$ & $38(20.5 \%)$ & $14(15.9 \%)$ & 14 (51.9\%) & $1(4.5 \%)$ \\
\hline Domain expert & $34(14.2 \%)$ & $17(9.1 \%)$ & $3(3.4 \%)$ & $10(37 \%)$ & $0(0 \%)$ \\
\hline Friend & $18(7.5 \%)$ & $12(6.4 \%)$ & $8(9 \%)$ & $2(7.4 \%)$ & $1(4.5 \%)$ \\
\hline Family & $10(4.1 \%)$ & $1(0.5 \%)$ & $0(0 \%)$ & $1(3.7 \%)$ & $0(0 \%)$ \\
\hline System expert & $1(0.4 \%)$ & $6(3.2 \%)$ & $2(2.2 \%)$ & $1(3.7 \%)$ & $0(0 \%)$ \\
\hline Other people & $4(1.6 \%)$ & $2(1 \%)$ & $1(1.1 \%)$ & $0(0 \%)$ & $0(0 \%)$ \\
\hline Online & $141(59 \%)$ & $113(61.1 \%)$ & $72(81.8 \%)$ & $9(33.3 \%)$ & 20 (91\%) \\
\hline General website & $80(33.4 \%)$ & $22(11.8 \%)$ & $36(40.9 \%)$ & $3(11.1 \%)$ & $8(36.4 \%)$ \\
\hline Web search engine & 36 (15\%) & $35(18.9 \%)$ & $15(17 \%)$ & $3(11.1 \%)$ & $6(27.3 \%)$ \\
\hline University website & $11(4.6 \%)$ & 27 (14.5\%) & $0(0 \%)$ & $2(7.4 \%)$ & $0(0 \%)$ \\
\hline News website & $1(0.4 \%)$ & $3(1.6 \%)$ & $11(12.5 \%)$ & $0(0 \%)$ & $3(13.7 \%)$ \\
\hline $\begin{array}{l}\text { Electronic library } \\
\text { resources }\end{array}$ & $0(0 \%)$ & $12(6.4 \%)$ & $3(3.4 \%)$ & $0(0 \%)$ & $0(0 \%)$ \\
\hline Wikipedia & $1(0.4 \%)$ & $6(3.2 \%)$ & $5(5.6 \%)$ & $0(0 \%)$ & $0(0 \%)$ \\
\hline Government website & $3(1.2 \%)$ & $3(1.6 \%)$ & $0(0 \%)$ & $0(0 \%)$ & 2 (9.1\%) \\
\hline Email archives & $4(1.6 \%)$ & $1(0.5 \%)$ & $1(1.1 \%)$ & $0(0 \%)$ & $0(0 \%)$ \\
\hline Personal website & $1(0.4 \%)$ & $2(1 \%)$ & $0(0 \%)$ & $0(0 \%)$ & $1(4.5 \%)$ \\
\hline Blogs & $2(0.8 \%)$ & $0(0 \%)$ & $0(0 \%)$ & $1(3.7 \%)$ & $0(0 \%)$ \\
\hline Online community & $1(0.4 \%)$ & $0(0 \%)$ & $1(1.1 \%)$ & $0(0 \%)$ & $0(0 \%)$ \\
\hline Personal files & $1(0.4 \%)$ & $1(0.5 \%)$ & $0(0 \%)$ & $0(0 \%)$ & $0(0 \%)$ \\
\hline Electronic course pack & $0(0 \%)$ & $1(0.5 \%)$ & $0(0 \%)$ & $0(0 \%)$ & $0(0 \%)$ \\
\hline Print & $30(12.6 \%)$ & $34(18.4 \%)$ & $2(2.3 \%)$ & $4(14.8 \%)$ & $1(4.5 \%)$ \\
\hline Book & $8(3.3 \%)$ & $24(12.9 \%)$ & $0(0 \%)$ & $0(0 \%)$ & $0(0 \%)$ \\
\hline Other reference source & $9(3.7 \%)$ & $6(3.2 \%)$ & $0(0 \%)$ & $3(11.1 \%)$ & $1(4.5 \%)$ \\
\hline Brochures & $6(2.5 \%)$ & $1(0.5 \%)$ & $1(1.1 \%)$ & $1(3.7 \%)$ & $0(0 \%)$ \\
\hline Newspaper & $6(2.5 \%)$ & $0(0 \%)$ & $1(1.1 \%)$ & $0(0 \%)$ & $0(0 \%)$ \\
\hline Magazine & $1(0.4 \%)$ & $2(1 \%)$ & $0(0 \%)$ & $0(0 \%)$ & $0(0 \%)$ \\
\hline Journal & $0(0 \%)$ & $1(0.5 \%)$ & $0(0 \%)$ & $0(0 \%)$ & $0(0 \%)$ \\
\hline Mass media & $1(0.4 \%)$ & $0(0 \%)$ & $0(0 \%)$ & $0(0 \%)$ & $0(0 \%)$ \\
\hline TV & $1(0.4 \%)$ & $0(0 \%)$ & $0(0 \%)$ & $0(0 \%)$ & $0(0 \%)$ \\
\hline Resources in total & $239(100 \%)$ & $185(100 \%)$ & $88(100 \%)$ & $27(100 \%)$ & $\begin{array}{c}22 \\
(100 \%)\end{array}$ \\
\hline
\end{tabular}

We were interested in comparing how the kinds of information resources or media selected by the 
subjects differed with respect to types of goals. Contrary to the general assumption about college students' information seeking, online information was not always a primary resource. Although online resources were used more frequently than human or print resources for most of goals, when the subjects engaged in some problem solving-related information seeking, they relied on human resources to the greatest extent (51.9\%). For personal information need, they turned to online resources to the extent of $59 \%$ while relying on human resources to the extent of $28 \%$. In cases of academic-related information seeking, the subjects relied on online resources to the extent of $61.1 \%$, but they still turned to human resources in $20.5 \%$ of the cases. The extent of using print resources varied depending on the types of goals. Not surprisingly, print resources were used most often for academic-related information seeking (18.4\%) and least often for entertainment $(2.3 \%)$ or routine $(4.5 \%)$ goals. It was interesting to note that the subjects employed print resources for problem solving to some extent (14.8\%).

More interesting results were found within the sub-categories of resources. Probably the most surprising finding was that web search engines were not necessarily always the most frequently used system for information finding. For both personal information need and entertainment-related information seeking goals, subjects selected general websites (33.4\% for personal information need and $40.9 \%$ for entertainment) more often than search engines (15\% for personal information need and $17 \%$ for entertainment). Rather, search engines (18.9\%) were chosen more often than general websites $(11.8 \%)$ in the cases in which subjects were looking for academic related information. It is because while the subjects already had their favorite sites for their personal information needs including sports, shopping, games and entertainment web sites, they may not have those favorite sites when they had to deal with in academic-related or problem-solving information seeking. Of online resources, university web sites (14.5\%) and electronic library resources (6.4\%) were used more often for academic related information seeking than any other purposes.

It should be noted that human resources were coded regardless of medium of contact: face-to-face, email, or phone. We believed that emailing someone to ask questions as opposed to obtaining information and searching on web sites should be differentiated because the former affords interaction with a "real person" while the latter gives interaction with documents. As Table 2 shows, the subjects relied more frequently on a "domain expert" than on their own friends for problem solving (37\%), personal information need (14.2\%), and academic achievement (9.1\%). Domain experts were their professors, teaching assistants, staff members, or any other people whom they considered as experts in a particular topic area. Friends were the people they would turn to consistently across all kinds of information seeking goals. Librarians or information professionals, coded here as "system experts," were contacted occasionally only for academic-related information seeking (3.2\%).

\section{Types of Information Tasks and Resources/Media Selection}

Selections of resources/media were compared with type of task, which was categorized by the kind of information sought. Tasks were characterized in terms of subject searching, fact retrieval, question answering, known item searching, and advice/recommendation/opinion seeking. Subject searching refers the cases in which the individuals looked for the kind of information about a topic that often required them to read, comprehend, and interpret the content from the information found. In the category of fact retrieval, a fact was defined as an indisputable truth, which can be numbers of short statements. The category of question answering was considered as tasks situated between subject searching and fact retrieval. There could be more than one answer for the question, but the question was not completely open-ended. The known item searching category refers to the cases in which the 
individuals already knew that there was such an information object. Further, they knew some parts of the characteristics of information, such as book title or author name.

Table 3. Information seeking tasks and resources/media used

\begin{tabular}{|c|c|c|c|}
\hline \multicolumn{1}{|c|}{ Task N (\%) } & Resources used in total & Resources used on average \\
\hline Subject searching & $89(37.2 \%)$ & $207(37.6 \%)$ & 2.32 \\
\hline \hline Question answering & $87(36.4 \%)$ & $179(32.6 \%)$ & 2.06 \\
\hline \hline Fact retrieval & $24(10.1 \%)$ & $62(11.3 \%)$ & 2.58 \\
\hline \hline Known item searching & $22(9.2 \%)$ & $65(11.8 \%)$ & 2.95 \\
\hline \hline Advice, recommendations, opinions & $17(7.1 \%)$ & $37(6.7 \%)$ & 2.17 \\
\hline Total & $239(100 \%)$ & $561(100 \%)$ & 2.24 \\
\hline
\end{tabular}

Table 3 summarizes the tasks that the subjects undertook and the number of information resources/media that they selected to find such information. It turned out that subject searching tasks (37.2\%) and question answering tasks (36.4\%) were the two most popular information tasks. On examining whether the subjects employed more or fewer information resources per information seeking episode depending on information task type, it was noticed that the subjects employed slightly fewer information resources for question answering tasks (2.06 on average) than for other types of tasks. Interestingly, the subjects used virtually three different kinds of resources (2.95) when they conducted known item searching.

Table 4. Information seeking tasks and resources/media selected

\begin{tabular}{|c|c|c|c|c|c|}
\hline Resource/Medium & $\begin{array}{l}\text { Subject } \\
\text { searching }\end{array}$ & $\begin{array}{l}\text { Question } \\
\text { answering }\end{array}$ & $\begin{array}{l}\text { Fact } \\
\text { retrieval }\end{array}$ & $\begin{array}{l}\text { Known-item } \\
\text { searching }\end{array}$ & $\begin{array}{c}\text { Advice, recommendation, } \\
\text { opinion }\end{array}$ \\
\hline Human resources & 27 (13.1\%) & 65 (36.3\%) & 10 (16.1\%) & $2(3.1 \%)$ & $28(75.7 \%)$ \\
\hline Domain expert & $13(6.2 \%)$ & 38 (21.2\%) & $2(3.2 \%)$ & $1(1.5 \%)$ & $10(27 \%)$ \\
\hline Friend & $11(5.3 \%)$ & $13(7.2 \%)$ & $6(9.6 \%)$ & $0(0 \%)$ & $11(29.7 \%)$ \\
\hline Family & $3(1.4 \%)$ & $4(2.2 \%)$ & $0(0 \%)$ & $0(0 \%)$ & 5 (13.5\%) \\
\hline System expert & $0(0 \%)$ & $7(3.9 \%)$ & $1(1.6 \%)$ & $1(1.5 \%)$ & $0(0 \%)$ \\
\hline Other people & $0(0 \%)$ & $3(1.6 \%)$ & $1(1.6 \%)$ & $0(0 \%)$ & $2(5.4 \%)$ \\
\hline Online & 152 (73.4\%) & $97(54.2 \%)$ & $42(67.8 \%)$ & 45 (69.2\%) & $9(24.3 \%)$ \\
\hline General website & $46(22.2 \%)$ & $57(31.8 \%)$ & $15(24.1 \%)$ & $16(24.6 \%)$ & $6(16.2 \%)$ \\
\hline Web search engine & $56(27 \%)$ & $16(8.9 \%)$ & $7(11.2 \%)$ & $14(21.5 \%)$ & $1(2.7 \%)$ \\
\hline University website & $17(8.2 \%)$ & 7 (3.9\%) & $11(17.7 \%)$ & $4(6.1 \%)$ & $1(2.7 \%)$ \\
\hline News website & $7(3.3 \%)$ & $6(3.3 \%)$ & $2(3.2 \%)$ & $2(3 \%)$ & $0(0 \%)$ \\
\hline $\begin{array}{l}\text { Electronic lib. } \\
\text { resources }\end{array}$ & $9(4.3 \%)$ & $1(0.5 \%)$ & $0(0 \%)$ & $5(7.6 \%)$ & $0(0 \%)$ \\
\hline Wikipedia & $11(5.3 \%)$ & $0(0 \%)$ & $0(0 \%)$ & $0(0 \%)$ & $0(0 \%)$ \\
\hline Government web site & $2(0.9 \%)$ & $4(2.2 \%)$ & $2(3.2 \%)$ & $0(0 \%)$ & $0(0 \%)$ \\
\hline Email archives & $0(0 \%)$ & $2(1.1 \%)$ & $3(4.8 \%)$ & $2(3 \%)$ & $0(0 \%)$ \\
\hline Personal website & $1(0.4 \%)$ & $1(0.5 \%)$ & $1(1.6 \%)$ & $1(1.5 \%)$ & $0(0 \%)$ \\
\hline Blogs & $2(0.9 \%)$ & $0(0 \%)$ & $0(0 \%)$ & $0(0 \%)$ & $1(2.7 \%)$ \\
\hline
\end{tabular}




\begin{tabular}{|c|c|c|c|c|c|}
\hline Online community & $1(0.4 \%)$ & $0(0 \%)$ & $1(1.6 \%)$ & $0(0 \%)$ & $0(0 \%)$ \\
\hline Personal files & $0(0 \%)$ & $3(1.6 \%)$ & $0(0 \%)$ & $0(0 \%)$ & $0(0 \%)$ \\
\hline $\begin{array}{l}\text { Electronic course } \\
\text { pack }\end{array}$ & $0(0 \%)$ & $0(0 \%)$ & $0(0 \%)$ & $1(1.5 \%)$ & $0(0 \%)$ \\
\hline Print & 28 (13.5\%) & $16(8.9 \%)$ & 10 (16.1\%) & $18(27.7 \%)$ & $0(0 \%)$ \\
\hline Book & $12(5.7 \%)$ & $6(3.3 \%)$ & $2(3.2 \%)$ & $12(18.4 \%)$ & $0(0 \%)$ \\
\hline $\begin{array}{c}\text { Other reference } \\
\text { source }\end{array}$ & $4(1.9 \%)$ & 7 (3.9\%) & $6(9.6 \%)$ & $3(4.6 \%)$ & $0(0 \%)$ \\
\hline Brochures & $7(3.3 \%)$ & $0(0 \%)$ & $1(1.6 \%)$ & $1(1.5 \%)$ & $0(0 \%)$ \\
\hline Newspaper & 3 (1.4\%) & $3(1.6 \%)$ & $1(1.6 \%)$ & $0(0 \%)$ & $0(0 \%)$ \\
\hline Magazine & $2(0.9 \%)$ & $0(0 \%)$ & $0(0 \%)$ & $1(1.5 \%)$ & $0(0 \%)$ \\
\hline Journal & $0(0 \%)$ & $0(0 \%)$ & $0(0 \%)$ & $1(1.5 \%)$ & $0(0 \%)$ \\
\hline Mass media & $0(0 \%)$ & $1(0.6 \%)$ & $0(0 \%)$ & $0(0 \%)$ & $0(0 \%)$ \\
\hline TV & $0(0 \%)$ & $1(0.6 \%)$ & $0(0 \%)$ & $0(0 \%)$ & $0(0 \%)$ \\
\hline Resources in total & 207 (100\%) & $179(100 \%)$ & $62(100 \%)$ & $65(100 \%)$ & $37(100 \%)$ \\
\hline
\end{tabular}

As shown in Table 4, the subjects in this study used human resources and online resources for different purposes. When looking for advice, recommendation, and opinion, they relied most heavily on human resources (75.7\%). For question answering tasks, they preferred relying on human resources (36.3\%) more often than they did for fact retrieval tasks (16.1\%) or subject searching tasks (13.1\%). Another interesting finding is that the subjects turned more frequently to domain experts when looking for answers (21.2\%) than when subject searching (6.2\%). When the subjects were looking for advice, recommendation, and opinion, they were likely turning to friends $(29.7 \%)$ or domain experts $(27 \%)$ more often than other people (5.4\%) or family (13.5\%). System experts (librarians or information professionals) were chosen relatively more frequently for the tasks of question answering (3.9\%) although subjects in general did not contact them very often.

Online resources were used most frequently for subject searching (73.4\%), known item searching (69.2\%), and fact retrieval (67.8\%). For the tasks of question answering (54.2\%) and advice, recommendation, and opinion (24.3\%), the subjects did not rely on online sources to a great extent as they tended to prefer contacting other people. Notably, they employed print resources relatively more frequently for known item searching (27.6\%) compared to other types of tasks ( $0 \%$ to $16.1 \%)$. No subject turned to print resources when they were seeking for advice, recommendation, and opinion. When examining specific types of online resources employed, we found that the subjects selected general websites more often than web search engines with the exception of the task of subject searching. The subjects turned to web search engines when they engaged in subject searching (27\%) or known item searching (21.5\%). When engaging in question answering tasks, however, they were likely to select general websites (31.8\%) rather than web search engines (8.9\%). On the other hand, the university websites (17.7\%) were selected mostly for the task of fact retrieval. Wikipedia was used solely for purposes of subject searching $(5.3 \%)$.

\section{Information Seeking as a Social Activity}

Qualitative analysis of interview transcripts revealed a number of distinct characteristics in the subjects' information seeking processes. First, the results of this study identified social support as an important 
factor influencing information seeking behavior, a finding similar to that of Hargittai \& Hinnant (2006). For both academic-related and everyday life information seeking (ELIS), subjects' information seeking was in fact a series of social activities. As seen in Tables 2 and 4, for some goals and tasks, participants preferred to use human resources more than online information resources. In further examining this finding, we noted that the participants considered human resources to be "shortcuts" as they felt that asking other people was easier and more time efficient than looking through numerous Web pages. As Weiler (2005) pointed out, time constraint is a significant factor influencing the choice of certain information resources and media. One subject said: "Okay, time is like a real big thing to me, so I always go to the most credible people. So I usually don't get wrong answers." When turning to other people for information, these subjects preferred email over face-to-face communication because email was perceived as being the most convenient and effective method for receiving the information given that some attributes of the information (links, titles, journal names, individuals' names) could be included in the email messages.

"Other people" are related to information seeking not only as a source of information but also as users of information. The fact that people sometimes engage in information seeking for others is well known in the field (Erdelez \& Rioux, 2000; Gross \& Saxton, 2001). There appear to be at least two information seeking situations in which this phenomenon occurs. The first entails people seeking for information on behalf of family members, friends, or others who will eventually use that information. The second entails situations in which information use will eventually affect others. For instance, a subject involved in preparing for a dorm-wide Halloween party sought information on how to obtain hot cider. This might have seemed a trivial question, but it was important to her to get the right information because having hot cider would affect many people who would attend the party. When another subject sought information on buying a gift for a teenager he was mentoring, he took the information seeking seriously to make the right choice.

Another related finding is that subjects occasionally wanted to verify information found in one source by comparing it with information from another source. A number of subjects said that they would feel more comfortable using information when they found that "two separate sources have similar information." In several cases, when they found information on the Web they verified it with their teaching assistants. When one subject was unsure about the first assignment for her course, she asked her classmates, checked out university websites, and stopped by the department office. It was only when at last she received an email from the course instructor that she was able to trust the information and stop her information seeking. All of these examples indicate that the subjects tended to use multiple resources for important information tasks, and human resources were often involved in the information seeking process either as an initial point at which to start the process or as a secondary or tertiary point to verify the information found.

\section{Conclusion}

This study enhances the understanding of a broader range of information activities with respect to diverse information types and sources by including not only online or print resources but also communication either face-to-face or computer mediated. Depending on the goals and tasks of the information seeking, the subjects chose resources or media that they were likely to employ. However, it does not mean that they had to choose a single resource to find information. Rather, the findings indicated that the subjects in this study sought information in both ways - information resources and human resources - as opposed to choosing a single kind of resource. In fact, they preferred to obtain the 
same content from two or more sources with the intention of cross-referencing. The subjects could then verify the content across the sources.

An integrated framework of information and communication behavior may not be a completely new framework, as Wilson (2000) has previously defined that human information behavior is a "totality of human behavior" including communication with others. The contribution of this paper is that the empirical findings reveal how information behavior and communication behavior are interwoven in the process of information seeking. Data herein were grounded in 245 information seeking episodes of 24 students from three institutions over ten-day periods. More importantly, this study found that the subjects' selection of information resources vary depending on the types of information seeking goals and tasks sought. The findings also indicated that the subjects engaged in information and communication behavior more strongly with problem-solving, personal information need, and academic-related information seeking episodes. When they were looking for information with the purpose of entertainment or routines to keep up to date, they were much less likely to get involved in both finding information from resources and communicating with other people. The results again demonstrated that the subjects engaged in both communication and information behaviors to a greater extent for the tasks of question-answering than any other types of task. Seeking advice, recommendations, and opinions is another type of task that the subjects appeared to deeply engage in information and communication behaviors.

The methodology used in this study has a number of implications for future information seeking research. Although the diary method has been used in previous studies (Byström, 2002; Cool \& Belkin, 2002; Rieh 2004; Xie, 2006), this study collected diary data over a longer period of time and for a greater variety of information seeking activities across the spectrum of work, school, and everyday life. In addition, subjects were instructed to keep records of the various aspects of their information seeking activities such as goals, topics, familiarity with topics, resources used, procedures, time taken, familiarity, confidence, and difficulty. Even though the diaries contained a wealth of data about the subjects' information seeking activities, the actual diary data were not included in the analyses. Rather, the purpose of gathering data through the diaries was to remind the subjects of the details of their information seeking episodes. Indeed, most entries recorded in the self-reported diaries helped both the interviewer and the subjects during the interview in that the interviewer was able to more fully discuss the details of their information seeking activities and the variety of information resources. The web-based method was also helpful in keeping track of the subjects' involvement over a relatively long time period so that reminders could be dispatched when no activity was reported for more than two days.

Consequently, only two cases of participant drop-out were recorded. As Internet use has become a daily routine for most people, the web-based diary can be widely employed in the field of human information behavior in the future.

\section{References}

Byström, K. (2002). Information and information sources in tasks of varying complexity. Journal of the American Society for Information Science and Technology, 53(7), 581-591.

Buckland, M. K. (1991). Information and information systems. Greenwood Press Westport, Conn.

Cool, C. \& Belkin, N. J. (2002). A Classification of Interactions with Information. Emerging frameworks and methods: Proceedings of the fourth international conference of library and information 
science (CoLIS4) H. Bruce, R. Fidel, P. Ingwersen \& P. Vakkari (Eds.), (pp. 1-15). Greenwood Village, Co: Libraries Unlimited.

Dilevko, J. \& Gottlieb, L. (2002). Print sources in an electronic age: A vital part of the research process for undergraduate students. Journal of Academic Librarianship, 28(6), 381-392.

Dresang, E. T. (2005). The information-seeking behavior of youth in the digital environment. Library Trends, 54(2), 178-196.

Erdelez, S. \& Rioux, K. (2000). Sharing information encountered for others on the Web. The New Review of information Behaviour Research, 1, 219-233.

Given, L. M. (2002). The academic and the everyday: Investigating the overlap in mature undergraduates' information-seeking behaviors. . Library \& Information Science Research, 24(1), 17-29.

Graham, L. \& Metaxas, P. T. (2003). Of course it's true: I saw it on the Internet!": Critical thinking in the Internet era. Communications of the ACM, 46(5), 71-75.

Gross, M. \& Saxton, M. L. (2001). Who wants to know? Imposed queries in the public libraries. Public Libraries, 40(3), 170-176.

Hargittai, E. \& Hinnant, A. (2006). Toward a social framework for information seeking. New directions in human information behavior A. Spink \& C. Cole (Eds.), (pp. 55-70). Netherlands: Springer.

Harris, R. M. \& Dewdney, P. (1994). Barriers to information: How formal help systems fail battered women. Greenwood Press. Westport: CT

Jones, S. (2002). The Internet goes to college: How students are living in the future with today's technology. Pew Internet \& American Life Project Washington,

D.C. http://www.pewinternet.org/pdfs/PIP_College_Report.pdf

Julien, H. \& Michels, D. (2000). Source selection among information seekers: Ideals and realities. Canadian Association for Information Science Proceedings of the 28th Annual Conference. http://www.slis.ualberta.ca/cais2000/julien.htm

Kuhlthau, C. C. (2004). Seeking meaning: A process approach to library and information services Libraries Unlimited (2nd ed.). Westport, CT.

Marchionini, G. (1995). Information seeking in electronic environments. Cambridge University Press New York

Morrison, D. M., Leigh, B. C. \& Gillmore, M. R. (1999). Daily data collection: A Comparison of three methods. The Journal of Sex Research, 36(1), 76.

Rice, R., McCreadie, M. \& Chang, S-J L. (2001). Accessing and browsing information and communication. The MIT Press Cambridge, MA

Rieh, S. Y. (2004). On the web at home: Information seeking and web searching in the home environment. Journal of the American Society for Information Science and Technology, 55(8), 743-753. 
Rieh, S. Y. \& Hilligoss, B. (in press). College students' credibility judgments in the information seeking process. Digital media, youth, and credibility, M. Metzger \& A. Flanagin (Eds.), MacArthur Foundation Series on Digital Media and Learning. Cambridge, MA: The MIT Press.

Shenton, A. K. \& Dixon, P. (2004). Issues arising from youngsters' information-seeking behavior. Library and Information Science Research, 26, 177-200.

Tapscott, D. (1997). Growing up digital: The rise of the net generation. McGraw-Hill New York

Toms, E. G. \& Duff, W. (2002). spent $1 \frac{1}{1 / 2}$ hours sifting through one large box....": Diaries as information behavior of the archives user: Lessons learned. Journal of the American Society for Information Science and Technology, 53(14), 1232-1238.

Valentine, B. (2001). The legitimate effort in research papers: student commitment versus faculty expectations. Journal of Academic Librarianship, 27(2), 107-115.

Weiler, A. (2005). Information-seeking behavior in generation Y students: Motivation, critical thinking, and learning theory. Journal of Academic Librarianship, 31(1), 46-53.

Wilson, T.D. (2000). Human information behavior. Informing Science, 3(2), 49-56. http://inform.nu/Articles/Vol3/v3n2p49-56.pdf

Xie, H. (2000), Shifts of interactive intentions and information-seeking strategies in interactive information retrieval. Journal of the American Society for Information Science, 51, 841-857.

Xie, H. (2006). Understanding human-work domain interaction: Implications for the design of a corporate digital library. Journal of the American Society for Information Science and Technology, 57(1), 128-143.

Zimmerman, D. H. \& Wieder, D. L. (1977). The diary: Diary-interview method. Urban Life, 5(4), 479-498. 